\title{
Growth of Staphylococcus epidermidis in Soft Agar in Relation to Respiration, Dehydrogenase Activity and Biotype
}

\author{
By TOSHICHIKA OHTOMO, YOSHITOSHI ICHIMAN, \\ SHIN-ICHI NARIKAWA AND KOSAKU YOSHIDA* \\ Department of Microbiology, St Marianna University School of Medicine, Takatsu-ku, \\ Kawasaki 213, Japan
}

(Received 22 June 1981; revised 4 January 1982)

\begin{abstract}
Using 200 fresh isolates of Staphylococcus epidermidis, the relationship between type of growth in soft-agar medium and respiration, dehydrogenase activity and biotype was investigated. When strains of S. epidermidis were cultured in Brain Heart Infusion medium containing $0.15 \%(\mathrm{w} / \mathrm{v})$ agar, the following different growth types were observed: compact colonial morphology with growth throughout the medium (type A), or with growth only at the surface (type B); and diffuse colonial morphology with growth throughout the medium (type C), growth only at the surface (type D), or growth from the surface to the middle of the tube (type E). Five representative strains of each growth type were studied and different results for cytochrome pattern, oxygen consumption and relative activities of lactic dehydrogenase and succinic dehydrogenase were obtained with different growth types. However, there was no correlation between growth type and biotype.
\end{abstract}

\section{INTRODUCTION}

Presence or absence of oxygen is regarded as an important determining factor in the metabolism of bacteria, especially Pasteurella pestis (Englesberg et al., 1954), Micrococcus (Kocur \& Mortensen, 1967), Streptococcus pneumoniae (Howden, 1976), Staphylococcus aureus (Frerman \& White, 1967; Goldenbaum \& White, 1974), and Staphylococcus epidermidis (Jacobs et al., 1963, Horan et al., 1978). A change of oxygen requirements in multiplying organisms is assumed to reflect alteration in the cytochrome type (Schaeffer, 1952; Jacobs \& Conti, 1965) and respiration capacity (Moss, 1956; Collins \& Lascelles, 1962).

Finkelstein \& Sulkin (1958) described a method for differentiating colonial morphologies of staphylococci under facultative anaerobic conditions in serum-soft agar (SSA). Yoshida et al. (1971) observed compact-type growth of $S$. epidermidis strains in SSA although diffuse-type growth was regarded as the typical colonial morphology for this species. This technique was later applied to taxonomic studies (Evans \& Kloos, 1972), serological typing (Yoshida et al., 1972; Nishine et al., 1976), and to the investigation of cell surface properties (Takahashi et al., 1977; Yoshida et al., 1977; Ohtomo et al., 1981). Recently we observed a variety of growth conditions and colonial morphologies of $S$. epidermidis strains in plain soft-agar (SA) medium. Attempts were therefore made to determine whether these findings relate to respiration systems and biotype.

\section{METHODS}

Strains. The 200 strains of $S$. epidermidis used were freshly isolated from clinical specimens at the Bacteriology Section, Clinical Laboratory, St Marianna University Medical School Hospital, Kawasaki, Japan. All strains were positive for catalase and arginine dehydrolase, all oxidized and fermented glucose as determined by $O F$ medium (Difco). They were negative for tube coagulase, clumping factor reaction and deoxyribonuclease, and all strains oxidized and fermented trehalose. Except for the strains that belonged to biotypes 3 and 4 (sensu Baird- 


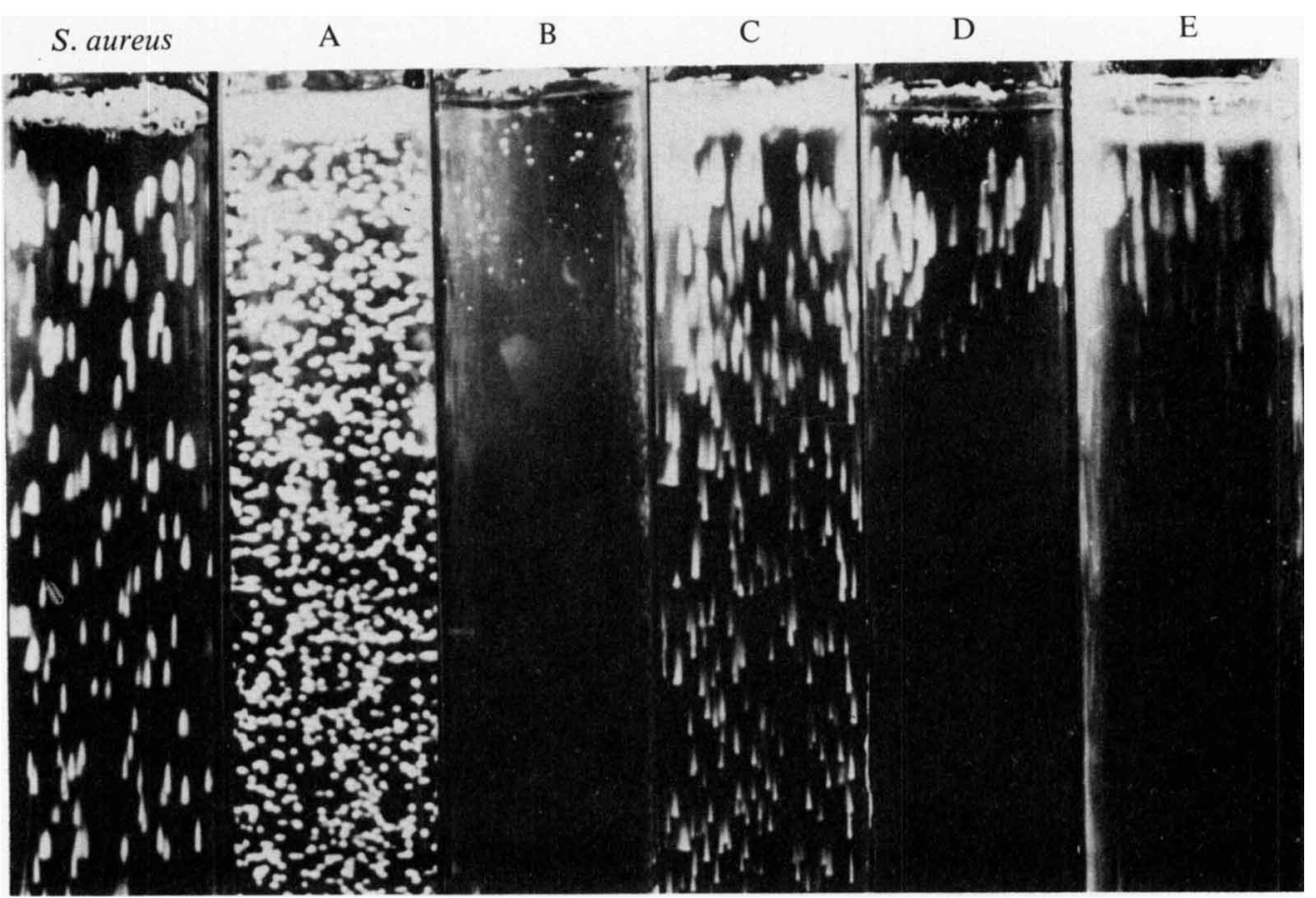

Fig. 1. Colonial morphologies and growth pattern of strains of $S$. aureus and $S$. epidermidis in soft agar. The designations $S$. aureus, A, B, C, D and E refer to the compact variant of $S$. aureus and representative strains of growth types A, B, C, D and E of $S$. epidermidis, respectively.

Parker, 1974), they were positive for phosphatase by the method of Pennock \& Huddy (1967) and sensitive to novobiocin; the strains gave variable results when tested for nitrate reduction by the methods of Oeding \& Digranes (1977) and Kloos \& Schleifer (1975). On the basis of these results, they were identified as $S$. epidermidis (sensu Kloos \& Schleifer, 1975). The compact variant of S. aureus strain Smith (Yoshida et al., 1974) was used as control.

Soft-agar technique. The SA technique was used as described previously (Yoshida, 1973). Organisms, grown in Brain Heart Infusion broth (BHI, Difco) at $37^{\circ} \mathrm{C}$ overnight, were diluted $1: 10^{6}$ with sterile saline; $0 \cdot 1 \mathrm{ml}$ of this cell suspension was combined with $10 \mathrm{ml}$ BHI (pH 7.4) containing $0 \cdot 15 \%$ (w/v) agar (Bacto-agar, Difco) and incubated at $37^{\circ} \mathrm{C}$ for $24 \mathrm{~h}$, after which colonial morphologies were determined. In these experiments strains exhibiting compact colonial morphology and growing throughout the medium were designated growth type A and those growing only near the surface were designated growth type B. Strains showing a diffuse type of colonial morphology and growing throughout the medium were designated growth type $\mathrm{C}$; diffuse colonies growing only near the surface were designated growth type $\mathrm{D}$, while those growing from the surface to the middle of the tube were designated growth type E (Fig. 1). Growth type of each strain was checked three times and found to be reproducible. Five randomly selected strains from each type were examined for cytochrome content, oxygen consumption and enzyme activity.

Preparation of whole cell extract. Strains inoculated into $500 \mathrm{ml} \mathrm{BHI}$ broth $\left(\mathrm{pH} \mathrm{7.4)}\right.$ were cultured at $37^{\circ} \mathrm{C}$ for $24 \mathrm{~h}$. After harvesting by centrifugation $(7000 \mathrm{~g})$ at $4{ }^{\circ} \mathrm{C}$, cell pellets were mixed with $10 \mathrm{ml}$ glass beads $(0 \cdot 17 \mathrm{~mm}$, B. Braun Apparatebau, Melsungen, F.R.G.) and $20 \mathrm{ml} \mathrm{0.3} \mathrm{M}$-phosphate buffer (pH 7.4) and then disrupted using a Braun cell disintegrator (type 853031 ) at $3000 \mathrm{rev} . \mathrm{min}^{-1}$ for $15 \mathrm{~min}$. The slurry was filtered through a sintered glass filter and centrifuged at $10000 \mathrm{~g}$ at $4{ }^{\circ} \mathrm{C}$ for $30 \mathrm{~min}$. Supernatants contained approximately $3 \mathrm{mg} \mathrm{protein} \mathrm{ml}^{-1}$ determined by the Lowry method and were stored at $-30^{\circ} \mathrm{C}$.

Identification of cytochrome types. Cytochrome types were identified by the methods of Jacobs \& Conti (1965) and Frerman \& White (1967) using a spectrophotometer (type LIV-300, Shimadzu, Co., Kyoto, Japan).

Assay for oxygen consumption. Oxygen consumption $\left(Q_{\mathrm{O}_{2}}\right)$ was measured by a Warburg technique at $37^{\circ} \mathrm{C}$. Each Warburg vessel contained $0.1 \mathrm{ml} 20 \%(\mathrm{w} / \mathrm{v}) \mathrm{KOH}$ in the centre well. The $Q_{\mathrm{O}_{2}}$ value was expressed as $\mu 1 \mathrm{O}_{2} \mathrm{~h}^{-1}(\mathrm{mg}$ dry $w t)^{-1}$ and was calculated from the linear portion of the oxygen uptake curve.

Enzyme assays. Relative lactic dehydrogenase activity was measured in a spectrophotometer (model UV-200, Shimadzu Co., Kyoto, Japan) by the method of Allen (1961). The reaction mixture contained $1.0 \mathrm{ml}$ sodium lactate 


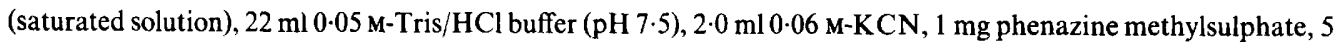
$\mathrm{mg} \mathrm{NAD}$ and $4 \mathrm{mg} p$-nitro blue tetrazolium. Whole cell extract $(0.2 \mathrm{ml})$ was added to a cuvette containing $30 \mathrm{ml}$ of the solution (kept at $37^{\circ} \mathrm{C}$ ) and mixed rapidly. The reduction rate of the nitro blue tetrazolium was measured at $60 \mathrm{~s}$ intervals at $625 \mathrm{~nm}$. Relative activity of succinic dehydrogenase was measured as follows by a method modified from Slater (1949). Methylene blue $(1.0 \mathrm{ml}), \mathrm{KCN}(1.0 \mathrm{ml})$ and sodium succinate $(0.8 \mathrm{ml})$ were added to the reaction mixture in a $20 \mathrm{ml}$ Thunberg tube containing $9.0 \mathrm{ml} 0 \cdot 1 \mathrm{M}$-phosphate buffer $(\mathrm{pH} 7 \cdot 5$ ). Diluted wholecell extract was placed in the side-arm and activity was determined by the reduction rate of methylene blue at 380 $\mathrm{nm}$ using a spectrophotometer (Spectronic-20, Shimadzu, Co., Kyoto, Japan). Distilled water without cell extract was used in control tubes.

Examination of the biotype. Strains were biotyped by the method of Baird-Parker (1974). Production of acetoin was determined by the procedure of Baird-Parker (1974) and aerobic acid production from lactose, maltose, and mannitol was examined by the method of Hugh \& Leifson (1953).

\section{RESULTS}

Growth type of S. epidermidis in soft agar

Two hundred strains of $S$. epidermidis were assigned to growth types as follows: type A (21), type B (8), type C (66), type D (33) and type E (72) (Table 1). Growth types A and C, which grow throughout the medium, would be expected to be facultatively anaerobic, while the behaviour of types $\mathrm{B}, \mathrm{D}$ and $\mathrm{E}$, in which colonies were restricted to the top of the medium, is presumed to reflect a degree of $\mathrm{O}_{2}$ dependence (Fig. 1).

\section{Relation of growth type to cytochrome}

Cell-free extracts obtained from five representative strains of each growth type exhibited generally similar absorption spectra between 450 and $650 \mathrm{~nm}$. However, differences were noted at the following wavelengths: $440,493,524,557,558,573,600$ and $602 \mathrm{~nm}$ (Fig. 2). It is notable that the spectra of cell-free extracts from growth type $\mathrm{A}$ and $\mathrm{C}$ strains showed similar degrees of absorption at 440, 524, 558 and $600 \mathrm{~nm}$. However an additional minor absorption peak at 510 $\mathrm{nm}$ was detected with growth type $\mathrm{C}$. The absorption maxima of strains of other growth types were: type B, 440, 473, 524, 558, and $602 \mathrm{~nm}$; type D, 440, 528, 557, 573 and $602 \mathrm{~nm}$; type E, 440, $528,557,588$ and $602 \mathrm{~nm}$. The compact variant of $S$. aureus Smith strain revealed different spectra from those of $S$. epidermidis strains. Each growth type showed characteristic spectra at 524 and/or 557 to $558 \mathrm{~nm}$ indicating the presence of type $a$ and/or type $b$ cytochromes. In strains of growth type $\mathrm{D}$ and $\mathrm{E}$, peaks were found at 573 and $588 \mathrm{~nm}$ suggesting the presence of type $c$ and $a_{1}$ cytochromes, respectively. However, the small peak at $493 \mathrm{~nm}$ observed with growth type B strains was difficult to interpret (Fig. 2).

\section{Relation of growth type to oxygen consumption}

These experiments were designed to compare the relation between growth type of $S$. epidermidis strains in SA and respiration capacities. Oxygen consumption rates (expressed as $Q_{\mathrm{O}_{2}} ; \mu \mathrm{O} \mathrm{O}_{2}$

Table 1. Relation of growth type in soft-agar to biotype of strains of $S$. epidermidis

\begin{tabular}{|c|c|c|c|c|c|c|c|}
\hline \multirow[b]{2}{*}{ Biotype } & \multicolumn{5}{|c|}{ No. of strains of growth type* } & \multirow{2}{*}{\multicolumn{2}{|c|}{$\begin{array}{cc}\text { Biotype as } & \begin{array}{c}\text { percentage of } \\
\text { total }\end{array}\end{array}$}} \\
\hline & A & B & $\mathrm{C}$ & $\mathrm{D}$ & $\mathrm{E}$ & & \\
\hline 1 & 0 & 0 & 17 & 0 & 45 & 62 & $31 \cdot 0$ \\
\hline 2 & 0 & 0 & 0 & 0 & 1 & 1 & 0.5 \\
\hline 3 & 0 & 0 & 2 & 6 & 0 & 8 & $4 \cdot 0$ \\
\hline 4 & 0 & 8 & 7 & 14 & 4 & 33 & $16 \cdot 5$ \\
\hline Non-typable & 21 & 0 & 40 & 13 & 22 & 96 & $48 \cdot 0$ \\
\hline Total & 21 & 8 & 66 & 33 & 72 & 200 & $100 \cdot 0$ \\
\hline $\begin{array}{l}\text { Growth type } \\
\text { as percentage } \\
\text { of total }\end{array}$ & $10 \cdot 5$ & $4 \cdot 0$ & $33 \cdot 0$ & $16 \cdot 5$ & $36 \cdot 0$ & $100 \cdot 0$ & \\
\hline
\end{tabular}

* The growth type of each strain was checked on three occasions. 


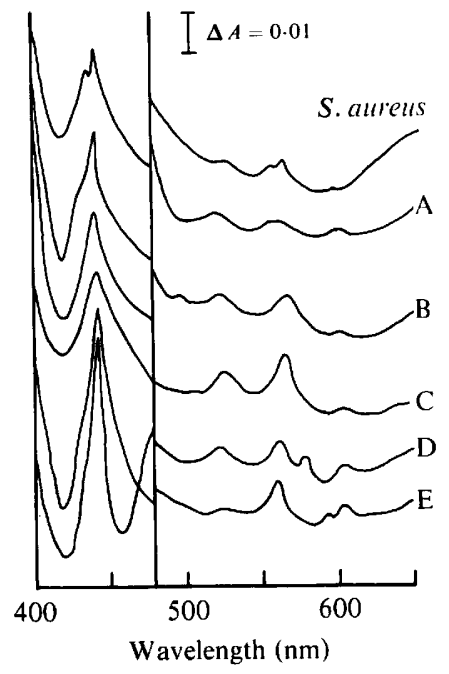

Fig. 2. Examples of absorption spectra of a strain of a compact variant of $S$. aureus strain Smith and five different growth types of $S$. epidermidis in soft agar (A-E).

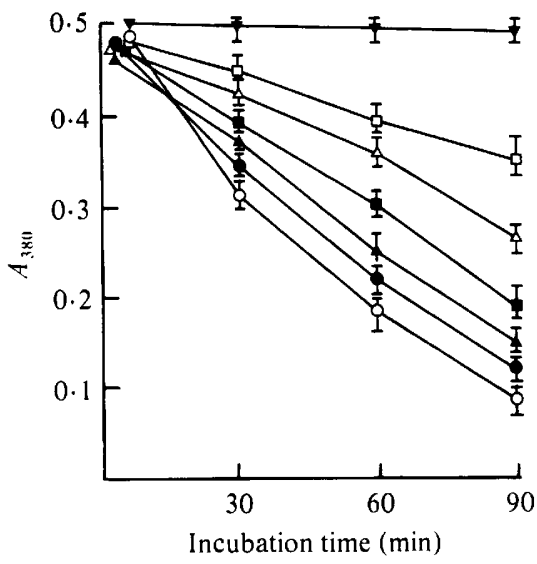

Fig. 3

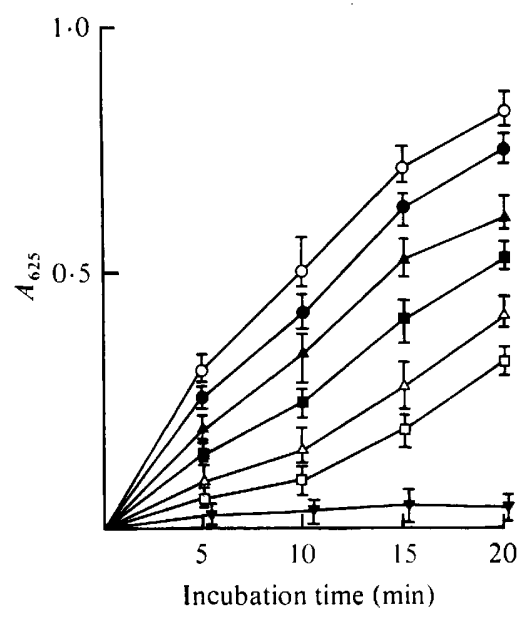

Fig. 4

Fig. 3. Succinic dehydrogenase activities of whole-cell extracts of the compact variant of Smith strain of $S$. aureus $(O)$ and representative strains of $S$. epidermidis of growth types $A(O), B(\triangle), C(\triangle), D(\square)$ and $E(\square)$ in soft agar; control, no cell extract added $(\nabla)$. Values represent mean \pm S.E. of four determinations.

Fig. 4. Lactic dehydrogenase activities of whole-cell extracts of the compact variant of Smith strain of $S$. aureus $(O)$ and representative strains of $S$. epidermidis of growth types A $(O), \mathrm{B}(\triangle), \mathrm{C}(\Delta), \mathrm{D}(\square)$ and $E(\square)$ in soft agar; control, no cell extract added. $(\nabla)$. Values represent mean \pm S.E. of four determinations.

$\mathrm{h}^{-1}(\mathrm{mg} \text { dry wt) })^{-1}$ increased as follows (mean values \pm S.D.) $: 79 \pm 3 \cdot 1,66 \pm 2 \cdot 8,59 \pm 4 \cdot 2,52 \pm$ $1 \cdot 5,49 \pm 2.9$ and $38 \pm 3.8 Q_{\mathrm{O} 2}$, for preparations from strains of $S$. aureus and of $S$. epidermidis growth types A, C, E, D and B, respectively. These results agreed with macroscopic findings of aerobic and anaerobic growth of the organisms in SA medium. 


\section{Relation of growth type to dehydrogenase activity}

A similar pattern of results was observed among the same growth type strains for relative activity of lactic dehydrogenase and succinic dehydrogenase. However, growth types $A$ and $C$ (facultatively anaerobic) showed higher activities than B, D and E (aerobic) (Figs 3 and 4). The compact variant of Smith strain of $S$. aureus showed considerably higher lactic dehydrogenase and succinic dehydrogenase activity than any of the $S$. epidermidis growth types. These results agreed with the results obtained for oxygen consumption described above.

\section{Relation of growth type to biotype}

None of 21 strains of growth type A could be classified according to biotype and all 8 strains of growth type B belonged to biotype 4 . Of 66 strains of growth type C, $17(26 \%), 2(3 \%)$ and 7 strains $(11 \%)$ were of biotype 1,3 and 4 , respectively, and 40 strains $(61 \%)$ were non-typable. Of 33 strains of growth type D, $6(18 \%), 14(42 \%)$ and $13(40 \%)$ strains were of biotype 3,4 and nontypable, respectively. Of the 72 strains of growth type E, $45(63 \%), 1(1 \%), 4(6 \%)$ and $22(31 \%)$ strains were of biotype $1,2,3$ and non-typable, respectively, indicating that there was no significant correlation between growth type and biotype.

\section{DISCUSSION}

Variation in biosynthesis and composition of the membrane-bound respiratory chain in growing staphylococci was related to oxygen tension (Jacobs et al., 1967; Frerman \& White, 1967). Also, greater cytochrome content and nitrate reducing ability in aerobically grown strains of $S$. epidermidis compared with anaerobically grown cultures has been reported (Jacobs et al., 1963; Jacobs \& Conti, 1965). In experiments reported here, cytochrome patterns of S. epidermidis strains belonging to growth types $\mathrm{A}$ and $\mathrm{C}$, which were facultatively anaerobic, agreed with reports for $S$. epidermidis by Jacobs \& Conti (1965) and for $S$. aureus (Goldenbaum \& White, 1974). The specific absorbances at 493,573 and $588 \mathrm{~nm}$ of strains of growth type B, D and E, which were aerobic, differed from each other and from types $A$ and $C$. In addition, the oxygen requirements of the various growth types of $S$. epidermidis strains correlated with the cytochrome patterns, suggesting a possible correlation between cytochrome systems and respiration capacity as postulated by Jacobs \& Conti (1965).

Gotz \& Schleifer (1978) and Sivakanesan \& Dawes (1980) noted higher dehydrogenase activities during aerobic growth of an $S$. epidermidis strain than during anaerobic growth. Also, Collins \& Lascelles (1962) and Stockland \& San Clemente (1968) found that dehydrogenase activity of aerobically cultured strains of $S$. aureus was higher than that of anaerobically grown cells. Relative activities of lactic dehydrogenase and succinate dehydrogenase obtained in our experiments were higher in strains that showed higher oxygen consumption. However, from these experiments it appeared that aerobic strains do not necessarily show greater dehydrogenase production and oxygen consumption than strains of the facultatively anaerobic growth type.

Finkelstein \& Sulkin (1958) reported that diffuse-type growth is a specific type of colonial morphology of S. epidermidis in SSA. However, Yoshida et al. (1971) noted compact-type strains of $S$. epidermidis in this medium and later Usui el al. (1979) obtained a specific substance from these organisms which reacted with serum components. Forsum et al. (1972) reported on the existence of compact-type strains in plain SA, whilst Evans \& Kloos (1972) showed various types of growth of members of the genera Micrococcus and Staphylococcus in an anaerobic zone of a SA medium. In our experiments five different growth types of the strains were observed in $S$. epidermidis, which were similar to those of strains of group A streptococci (Whittenbury, 1978). The mechanism of compact-colony formation of $S$. aureus and some strains of $S$. epidermidis in SSA has already been elucidated by Yoshida et al. (1971) and Usui et al. (1979). In contrast, the mechanism of the appearance of different colonial morphologies of $S$. epidermidis in plain SA is unknown; however, there was no significant relation between colonial morphologies and biotype. The biological significance of growth type of the strains and possible classification of other species within the genus Staphylococcus require to be elucidated; such studies are currently being performed in our laboratory. 


\section{REFERENCES}

Allen, J. (1961). Multiple forms of lactate dehydrogenase in tissues of the mouse; their specificity, cellular localization and response to altered physiological conditions. Annals of the New York Academy of Sciences 94, 937-951.

BAIRD-PARKER, A. C. (1974). The basis for the present classification of staphylococci and micrococci. $A n$ nals of the New York Academy of Sciences 236, 7-13.

Collins, F. M. \& LASCELles, J. (1962). The effect of growth conditions on oxidative and dehydrogenase activity in Staphylococcus aureus. Journal of General Microbiology 29, 531-535.

ENGlesberG, E., LeVY, J. B. \& Gibor, A. C. (1954). Some enzymatic changes accompanying the shift from anaerobiosis to aerobiosis in Pasteurella pestis. Journal of Bacteriology 68, 178-185.

Evans, J. B. \& KLoos, W. E. (1972). Use of shake cultures in a semisolid thioglycolate medium for differentiating staphylococci from micrococci. Applied Microbiology 23, 326-331.

Finkelstein, R. A. \& Sulkin, S. E. (1958). Characteristics of coagulase negative staphylococci in serumsoft agar. Journal of Bacteriology 75, 339-343.

Forsum, U., Forsgen, A. \& HJelum, E. (1972). Role of protein $\mathrm{A}$ in the serum-soft agar technique. Infection and Immunity 6, 583-586.

Frerman, F. E. \& White, D. C. (1967). Membrane lipid changes during formation of a functional electron transport system in Staphylococcus aureus. Journal of Bacteriology 94, 1868-1874.

Goldenbaum, P. E. \& White, D. C. (1974). Role of lipid in the formation and function of the respiratory system of Staphylococcus aureus. Annals of the New York Academy of Sciences 236, 115-123.

GotZ, F. \& SCHLEIFER, K. H. (1978). Biochemical properties and the physiological role of the fructose 1,6-bisphosphate activated L-lactate dehydrogenase from Staphylococcus epidermidis. European Journal of Biochemistry 90, 555-561.

Horan, N. J., Midgley, M. \& Dawes, E. A. (1978). Anaerobic transport of serine and 2-aminoisobutyric acid by Staphylococcus epidermidis. Journal of General Microbiology 109, 119-126.

HowDEN, R. (1976). Use of anaerobic culture for the improved isolation of Streptococcus pneumoniae. Journal of Clinical Pathology 29, 50-53.

Hugh, R. \& Leifson, E. (1953). The taxonomic significance of fermentative versus oxidative metabolism of carbohydrates by various Gram-negative bacteria. Journal of Bacteriology 66, 24-26.

JACOBS, N. J. \& CONTI, S. F. (1965). Effect of hemin on the formation of the cytochrome system of anaerobically grown Staphylococcus epidermidis. Journal of Bacteriology 89, 675-679.

Jacobs, N. J., Johantges, J. \& Deibel, R. H. (1963). Effect of anaerobic growth on nitrate reduction by Staphylococcus epidermidis. Journal of Bacteriology 85, 782-787.

JACOBS, N. J., Maclosky, E. R. \& CoNTI, S. F. (1967). Effect of oxygen and heme on the development of a microbial respiratory system. Journal of Bacteriology 93, 278-285.

KLOOS, W. E. \& Schleifer, K. H. (1975). Simplified schema for routine identification of human Staphylo- coccus species. Journal of Clinical Microbiology 1, 8288.

Kocur, M. \& Mortensen, N. (1967). Comparison of methods for estimation of anaerobic production of acid from glucose and mannitol in staphylococci and micrococci. Acta pathologica et microbiologica scandinavica 71, 141-146.

Moss, F. (1956). Adaptation of the cytochromes of Aerobacter aerogenes in response to environmental oxygen tension. Australian Journal of Experimental Biological \& Medical Science 34, 395-406.

Nishine, A., IWAMI, S., Takahashi, M. \& Yoshida, K. (1976). Epidemiologic application of a typing method for Staphylococcus epidermidis strains by the serum-soft agar technic. American Journal of Clinical Pathology 65, 711-714.

Oeding, P. \& Digranes, A. (1977). Classification of coagulase-negative staphylococci in the diagnostic laboratory. Acta pathologica et microbiologica scandinavica 85, 136-142.

Oнtomo, T., Yoshida, K. \& San Clemente, C. L. (1981). Effect of bile acid derivatives on taurine biosynthesis and extracellular slime production in encapsulated Staphylococcus aureus S-7. Infection and Immunity 31, 798-807.

Pennock, C. A. \& Huddy, R. B. (1967). Phosphatase reaction of coagulase-negative staphylococci and micrococci. Journal of Pathology and Bacteriology 93 , 685-688.

SCHAEFFER, P. (1952). Recherches sur le métabolisme bactérien des cytochromes et des porphyrines. 1. Disparition partielle des cytochromes par culture anaérobie chez certaines bactéries aérobies facultatives. Biochimica et biophysica acta 9, 261-270.

Sivakanesan, R. \& Dawes, E. A. (1980). Anaerobic glucose and serine metabolism in Staphylococcus epidermidis. Journal of General Microbiology 118, 148 157.

SLATER, E. C. (1949). A respiratory catalyst required for the reduction of cytochrome $c$ by cytochrome $b$. Biochemical Journal 45, 14-30.

Stockland, A. E. \& San Clemente, C. L. (1968). Lactate dehydrogenase activity in certain strains of Staphylococcus aureus. Journal of Bacteriology 95, 7480.

Takahashi, M., Yoshida, K. \& San Clemente, C. L. (1977). Relation of colonial morphologies in soft agar to morphological and biological properties of the K-9 strain of Klebsiella pneumoniae and its variants. Canadian Journal of Microbiology 23, 448-451.

Usui, Y., Narikawa, S., Ichiman, Y. \& Yoshida, K. (1979). Isolation of serologically heterologous compact-colony forming active substance from a strain of Staphylococcus epidermidis. Japanese Journal of Bacteriology 34, 847-851.

WhITTENBURY, R. (1978). Biochemical characteristics of streptococcus species. In Streptococci, pp. 51-69. Edited by F. A. Skinner \& L. B. Quesnel. London: Academic Press.

YosHIDA, K. (1973). Compact colony forming activity and the effect of compact-type growth of Staphylococcus aureus strains in serum-soft agar. American Journal of Clinical Pathology 59, 412-416. 
Yoshida, K., Smith, M. R. \& NaIto, Y. (1971). Compact-type growth of Staphylococcus epidermidis strains in serum-soft agar. Infection and Immunity 4, 656-657.

Yoshida, K., Smith, M. R. \& NaIto, Y. (1972). Serological typing of Staphylococcus epidermidis strains by the serum-soft agar technique. Infection and Immunity 5, 8-11.
Yoshida, K., Nakamura, A., Ohtomo, T. \& Iwami, S. (1974). Detection of capsular antigen production in unencapsulated strains of Staphylococcus aureus. Infection and Immunity 9, 620-623.

Yoshida, K., OHTomo, T. \& Minegishi, Y. (1977). Mechanism of compact-colony formation by strains of Staphylococcus aureus in serum-soft agar. Journal of General Microbiology 98, 67-75. 